\title{
Preliminary Study on Machining Condition Monitoring System using 3-Channel Force Sensor Analyzed by I-kaz Multilevel Method
}

\author{
Z. Karim ${ }^{\#}$, M.Z. Nuawi*, J.A. Ghani*, A.Y. Md. Said ${ }^{\#}$ \\ \# Mechanical and Manufacturing Engineering Department, Universiti Kuala Lumpur, Malaysia France Institute, 43650 Selangor, Malaysia \\ E-mail: zailan@unikl.edu.my
}

* Mechanical and Material Engineering Department, Universiti Kebangsaan Malaysia, 43650 Selangor, Malaysia.

\begin{abstract}
Cutting tool wear is one of the major problems affecting the finished product in term of surface finish quality, dimensional precision and the cost of the defect. This paper discusses the preliminary study on machining condition monitoring system using force data captured using 3-channel force sensor. The data were analyzed by I-kaz multilevel method to monitor the flank wear progression during the machining. The flank wear of the cutting insert was measured using Moticom magnifier under two different operational conditions in turning process. A 3-channel Kistler force sensor was assembled to hold the tool holder to measure the force on the cutting tool in the tangential, radial and feed direction during the machining process. The signals were transmitted to the data acquisition equipment, and finally to the computer system. I-kaz multilevel method was used to identify and characterize the changes in the signals from the sensors under two different experimental set up. The values of I-kaz multilevel coefficients for all channels are strongly correlated with the cutting tool wear condition. This preliminary study can be further developed to efficiently monitor and predict flank wear level which can be used in the real machining industry.
\end{abstract}

Keywords - Condition monitoring; I-kaz multilevel; tool wear; flank wear; signal processing

\section{INTRODUCTION}

Cutting tool failures represent approximately $20 \%$ of the downtime of machine tools in industries [1]. The cost of cutting tools and the replacement represent between 3 to $12 \%$ of total production costs $[2,3]$. Tool wear has a direct impact on the work piece in term of surface finish quality, dimensional precision and the cost of the defect finish product [4]. Due to this, there is a need to develop a tool wear detection system using an accurate and a reliable tool condition monitoring system [5]. Different methods have been proposed for tool wear monitoring, which can be identified as two types, direct and indirect methods. In direct methods, actual geometric changes of the tool wear can be identified but are very difficult to install due to the continuous contact between the tool and the workpiece and the presence of coolant fluids. Thus, the direct method is limited by these difficulties [6, 7]. Indirect methods have the advantages of being less complicated setup and greater suitability to practical application. These methods correlate the signal features extracted through signal processing steps to tool wear states. Indirect methods include those based on sensing of the acoustic emission [8], cutting forces [9], motor power [10] and other parameter. This study proposes the application of a 3-channel force sensor for monitoring cutting tool wear by measuring cutting tool force and analyzing its signal using a new statistical-based method called Multilevel Integrated Kurtosis based Algorithm for ZNotch Filter or I-kaz Multilevel [11]. The experiments were carried out using Haas-10 CNC turning machines to collect data which relate the signal features from cutting tool deflection to gradual flank wear or VB.

\section{METHODOLOGY}

\section{A. Design and procedure of the experiment}

The material and cutting tool used in this study were AISI H13 and DNMG150604 H1000 respectively. The machining tests were carried out on Haas-10 CNC turning machine in dry cutting condition. A 3-channel Kistler force sensor was assembled to hold the tool holder to measure the force on the cutting tool in the tangential, radial and feed direction during the machining process. The signals were transmitted to the data acquisition equipment, and finally to the computer system. The machining process was done in two different depth of cut (DOC), $0.4 \mathrm{~mm}$ and $0.6 \mathrm{~mm}$ while the cutting speed and the feed rate were kept constant at $130 \mathrm{~m} / \mathrm{min}$ and $0.14 \mathrm{~mm} / \mathrm{rev}$ respectively. During the experiment, the insert was periodically removed from the tool holder and the flank 
wear was measured using Moticom 3M magnifier. The operation was stopped when flank wear value (VB) approximately reached $0.3 \mathrm{~mm}$.

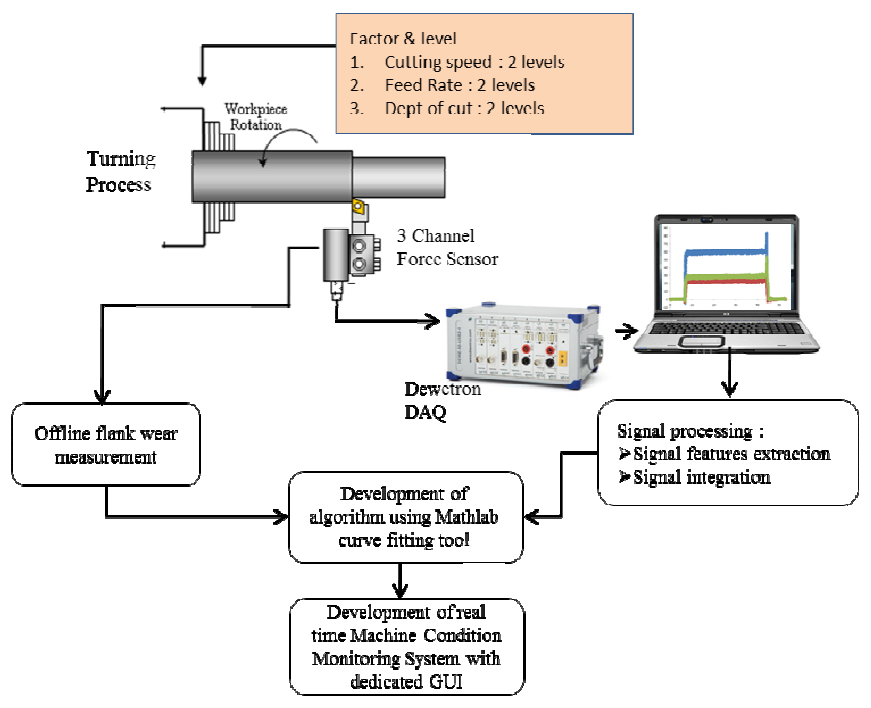

Fig. 1 Experiment set-up

\section{B. I-kaz Multilevel Coefficient (LZœ)}

The development of I-kaz Multilevel coefficient $\left({ }^{\mathrm{L}} \mathrm{Z}^{\infty}\right)$ was inspired by the original $\mathrm{I}-\mathrm{kaz}^{\mathrm{TM}}\left(\mathrm{Z}^{\infty}\right)$ which was pioneered by M.Z. Nuawi et al. [17].The new symbol for Ikaz Multilevel coefficient is defined as ${ }^{\mathrm{L}} \mathrm{Z}^{\infty}$ in which $L$ is referring to the number of order of signal decomposition. The decomposition of signals in time domain into more frequency bands is to get a better coefficient response especially in the lower part of the frequency spectrum. The new developed coefficient $\left({ }^{\mathrm{L}} Z^{\infty}\right)$ is expected to have more sensitivity towards amplitude and frequency change in a signal. In I-kaz multilevel method, signal decomposition using $L^{\text {th }}$ order of Daubechies theorem will result in $L$ number of frequency bands.

The I-kaz Multilevel coefficient can be calculated as [12]:

${ }^{L} Z^{\infty}=\frac{1}{n} \sqrt{K_{1} s_{1}{ }^{4}+K_{2} s_{2}{ }^{4}+K_{3} s_{3}{ }^{4} \ldots+K_{L} s_{L}{ }^{4}}$

Where $\mathrm{L}$ indicates the order of signal decomposition.

The standard deviation in Eq. 1 can be calculated using Eq. 2 [15]:

$s=\left(\frac{1}{n} \sum_{i=1}^{n}\left(x_{i}-\bar{x}\right)^{2}\right)^{\frac{1}{2}}$

The value of Kurtosis K, for descrete data sets in Eq. 4 is defined as in Eq. 6:

$\mathrm{K}=\frac{1}{n s^{4}} \sum_{i=1}^{n}\left(x_{i}-\bar{x}\right)^{4}$

Where $x_{i}$ is the value of the data point and $\bar{X}$ is the mean of the data and $s$ is the standard deviation value.

\section{RESULTS AND DISCUSSION}

\section{A. Flank wear responses}

Two experiments were performed to collect the cutting force signal during the machining process. . The signals and tool wear data were recorded from the first cutting until the cutting tool wear reached $0.3 \mathrm{~mm} \mathrm{[13].} \mathrm{The} \mathrm{overall} \mathrm{results} \mathrm{of}$ the machining processes were recorded and figure 2 and figure 3 were plotted. The regression lines were calculated as 0.9892 and 0.9951 for DOC at $0.4 \mathrm{~mm}$ and at $0.6 \mathrm{~mm}$ respectively. From these figures, it can be clearly seen that the flank wear of the cutting tools can be divided into three stages, break-in period, steady state and failure region. As for example, from Fig. 2, at the DOC $0.4 \mathrm{~mm}$, the VB value for the break-in period is from $0 \mathrm{um}$ to $60 \mathrm{um}$, steady-state is $60 \mathrm{um}$ to $160 \mathrm{um}$ and failure-region is $160 \mathrm{um}$ to $350 \mathrm{um}$. The flank wear measurement reaches $0.3 \mathrm{~mm}$ faster with the increase of depth of cut.

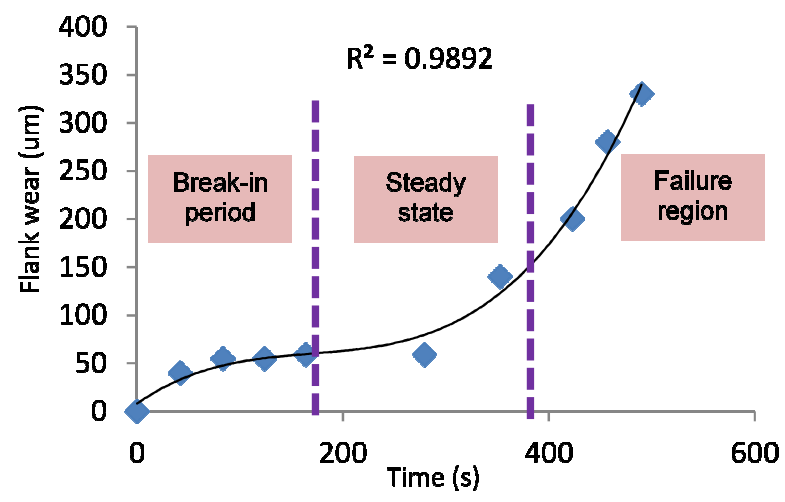

Fig. 2 The plot of VB vs. tool travel at DOC $=0.4 \mathrm{~mm}$

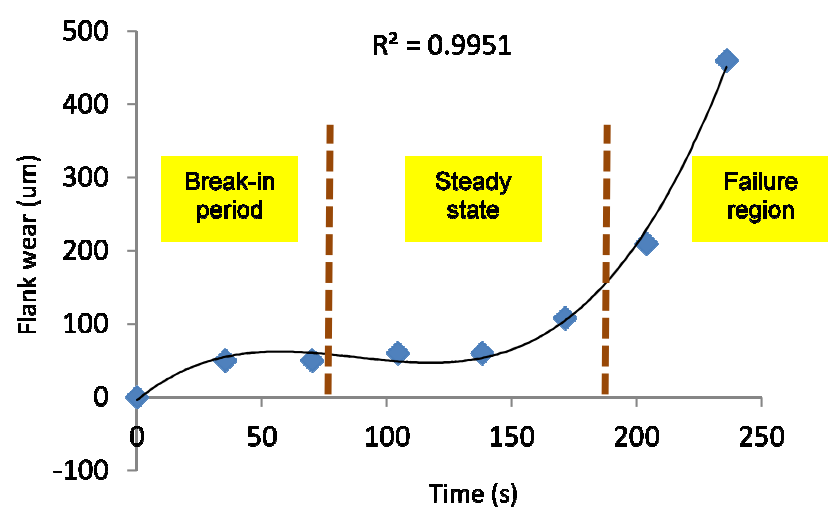

Fig. 3 The plot of VB vs. tool travel at DOC $=0.6 \mathrm{~mm}$

\section{B. Signal analysis}

I-kaz multilevel coefficient, ${ }^{7} Z^{\infty}$ was utilized in the measurement of the scattered raw data in the time domain. This method is very effective in measuring distances of each data point from a centroid signal [12]. The relationship between ${ }^{7} Z^{\infty}$ coefficient and flank wear was plotted as shown in Fig. 4 and Fig. 5. 


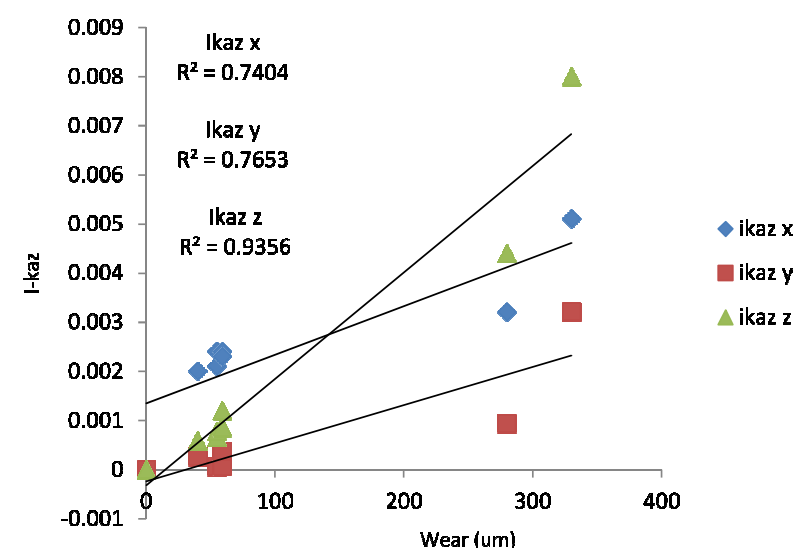

Fig. 4 Correlation between the I-kaz ${ }^{\mathrm{TM}}$ multilevel coefficient and flank wear at $0.4 \mathrm{~mm}$ depth of cut

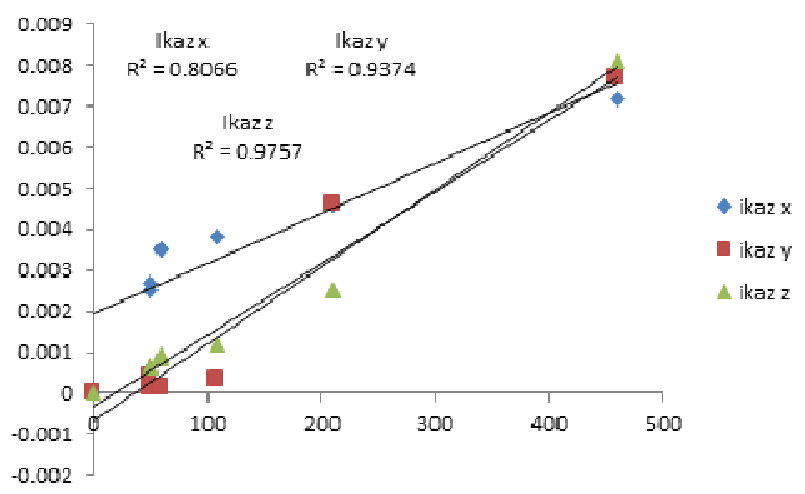

Fig. 5 Correlation between the I-kaz ${ }^{\mathrm{TM}}$ multilevel coefficient and flank wear at $0.6 \mathrm{~mm}$ depth of cut

Fig.4 and Fig. 5 show that the I-kaz multilevel coefficients calculated from the force signals captured during the machining process have linear correlation with the VB (flank wear). Thus, when the flank wear on the cutting insert increase, the ${ }^{7} Z^{\infty}$ coefficient values also increase linearly. The correlation value $\left(\mathrm{R}^{2}\right)$ between the ${ }^{7} \mathrm{Z}^{\infty}$ coefficient values and VB values is good and the average was calculated to be 0.8602 .

Fig. 6 and Fig. 7 show the sample of force vs. time plot, the wear condition and also the I-kaz coefficient value for machining result at DOC $0.4 \mathrm{~mm}$ for run 2. Fig. 8 and Fig. 9 show similar information as in Fig. 6 \& Fig. 7, but this time at run 6 . VB value at run 2 and run 6 are at 21 um and 212 um and they are represented by different I-kaz multilevel coefficient values which are 0.0035 and 0.0045 respectively.

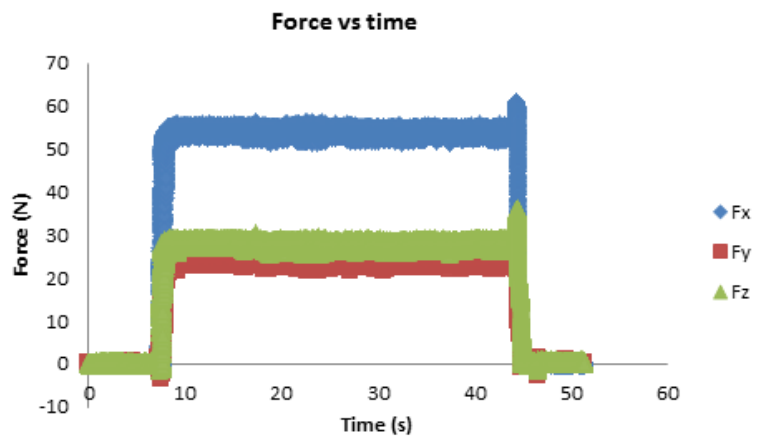

Fig. 6 Force vs. time for Run 2 at DOC $0.4 \mathrm{~mm}$

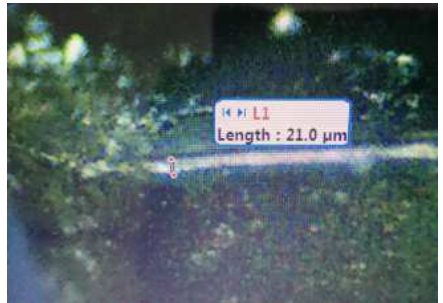

I-kaz coef. $=0.0035$

Fig. 7 Wear status and I-kaz coefficient values for Run 2 at DOC $0.4 \mathrm{~mm}$

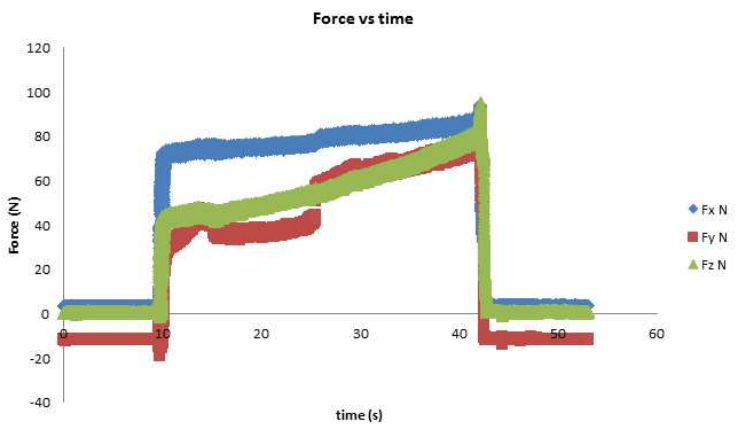

Fig. 8 Force vs. time for Run 6 at DOC $0.4 \mathrm{~mm}$

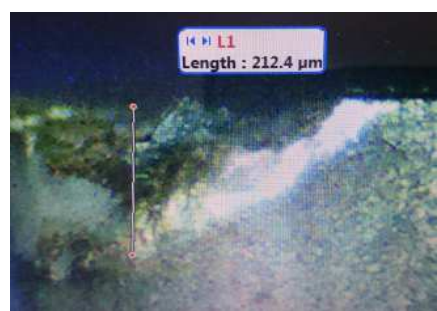

I-kaz coef. $=0.0045$

Fig. 9 Wear status and I-kaz coef. Values for Run 6 at DOC $0.4 \mathrm{~mm}$

\section{CONCLUSIONS}

This study aimed to investigate the correlation between flank wear and cutting force in $\mathrm{CNC}$ turning processes, using a 3-channel Kistler force sensor. A new correlation has been developed between the I-kaz multilevel coefficient calculated from the force signal and flank wear data. The regression trend of its correlation shows a linear line with the R-square values of the regression coefficient between 0.74 and 0.97. The R-square values show good correlation between I-kaz multilevel coefficient and the flank wear status. Thus, the I-kaz multilevel coefficients can be used as the input signal features to the decision making algorithm such as in Mahalanobis Taguchi System, artificial intelligence (AI), artificial neural network (ANN), statistical analysis and others. By applying the decision making algorithm, the flank wear status can be predicted and able to give an early indication of flank wear status in the cutting tool without disassembling it to measure the actual flank wear. This will promotes the uninterrupted and higher machining efficiency in machining operation in the production. 


\section{ACKNOWLEDGMENT}

The authors wish to express their gratitute to Universiti Kebangsaan Malaysia and Ministry of Higher Education, through the Grant 03-01-02-SF0843, for supporting this research.

\section{REFERENCES}

[1] P. Bhattacharyyaa, D. Senguptaa, S. Mukhopadhyay, "Cutting forcebased real-time estimation of tool wear in face milling using a combination of signal processing techniques," Mechanical Systems and Signal Processing 21 (2007) 2665-2683

[2] S. Kurada, C. Bradley, A review of machine vision sensors for tool condition monitoring, Comput. Ind. 34 (1997) 55-72.

[3] M. Castejon, E. Alegre, J. Barreiro, L.K. Hernandez, On-line tool wear monitoring using geometric descriptors from digital images, Int. J. Mach. Tools Manuf. 47 (2007) 1847-1853.

[4] Anayet U. Patwari1, M. N. Mahmood, M.D Arif, Improvement of Machinability of Mild Steel during Turning Operation by Magnetic Cutting, International Journal on Advanced Science, Engineering and Information Technology. Vol. 2 (2012) No. 3.

[5] B. Kilundu, et al., Tool wear monitoring by machine learning techniques and singular spectrum analysis, Mechanical Systems and Signal Processing (2010), doi:10.1016/j.ymssp.2010.07.014

[6] H.H. Shahabi, M.M. Ratnam, In-cycle monitoring of tool nose wear and surface roughness of turned parts using machine vision, Int. J. Adv. Manuf. Tech. 40 (2009) 1148-1157.

[7] J.A. Ghani, M. Rizal, M.Z. Nuawi, C.H.C. Haron, R. Ramli, Statistical analysis for detection of cutting tool wear based on regression model, in: Proceedings of the International MultiConference of Engineers and Computer Scientists 2010, vol. III, 2010, pp. 1784-1788.

[8] Teti R, Manzoni A (1998) Tool Wear State Identification by Fuzzy Logic Processing of Fused Sensor Data. 1st CIRP Int. Sem. on ICME, Capri, 1-3 July, 687-691.

[9] Axinte D (2007) An Experimental Analysis of Damped Coupled Vibrations in Broaching. International Journal of Machine Tools and Manufacture 47(14):2182-2188.

[10] Shi D, Axinte D, Gindy N (2007) Development of an Online Machining Process Monitoring System: A Case Study of the Broaching Process. International Journal of Advanced Manufacturing Technology 34(1-2):34-46.

[11] Z. Karim, M.Z. Nuawi, J.A. Ghani, S. Abdullah and M.J. Ghazali. Optimization of Integrated Kurtosis-Based Algorithm for Z-Filter (IkazTM) Coefficient Using Multi Level Signal Decomposition Technique. World Applied Sciences Journal 14 (10): 1541-1548, 2011

[12] Nuawi M.Z., M.J.M. Nor, N. Jamaludin, S. Abdullah, F. Lamin and C.K.E. Nizwan, 2008. Development of Integrated Kurtosis-Based Algorithm for Z-Filter Technique. Journal of Applied Sciences, 8: 1541-1547.

[13] ISO (International Organization for Standardization) (Ed.), Tool-life Testing with Single-Point Turning Tools (ISO 3685), 2nd edition, Reference Number ISO 3685: (1993) (E).

[14] J.A. Ghani, M. Rizal, M.Z. Nuawi, M.J. Ghazali, C.H.C. Haron, Monitoring online cutting tool wear using low-cost technique and user friendly GUI, Wear 271 (2011) 2619-2624 